\title{
Assessment of crusting effects on interrill erosion by laser scanning
}

\author{
Yaxian Hu ${ }^{\text {Corresp., } 1,2}$, Wolfgang Fister ${ }^{2}$, Yao He ${ }^{1}$, Nikolaus J. Kuhn ${ }^{2}$ \\ ${ }^{1}$ State Key Laboratory of Soil Erosion and Dryland Farming on the Loess Plateau, Institute of Soil and Water Conservation, Northwest A\&F University, \\ Yangling, Shaanxi, China \\ 2 Physical Geography and Environmental Change, Department of Environmental Sciences, University of Basel, Basel, Switzerland \\ Corresponding Author: Yaxian $\mathrm{Hu}$ \\ Email address: huyaxian@nwafu.edu.cn
}

Background. Crust formation affects soil erosion by raindrop impacted flow through changing particle size and cohesion between particles on the soil surface, as well as surface microtopography. Therefore, changes in soil microtopography can, in theory, be employed as a proxy to reflect the complex and dynamic interactions between crust formation and erosion caused by raindrop-impacted flow. However, it is unclear whether minor variations of soil microtopography can actually be detected with tools mapping the crust surface, often leaving the interpretation of interrill runoff and erosion dynamics qualitative or even speculative.

Methods. In this study, we used a laser scanner to measure the changes of the microtopography of two soils placed under simulated rainfall in experimental flumes and crusting at different rates. The two soils were of the same texture, but under different land management, and thus organic matter content and aggregate stability. To limit the amount of scanning and data analysis in this exploratory study, two transects and four subplots on each experimental flume were scanned with a laser in one-millimeter interval before and after rainfall simulations.

Results. While both soils experienced a flattening, they displayed different temporal patterns of crust development and associated erosional responses. The laser scanning data also allowed to distinguish the different rates of developments of surface features for replicates with extreme erosional responses. The use of the laser data improved the understanding of crusting effects on soil erosional responses, illustrating that even limited laser scanning provides essential information for quantitatively exploring interrill erosion processes. 


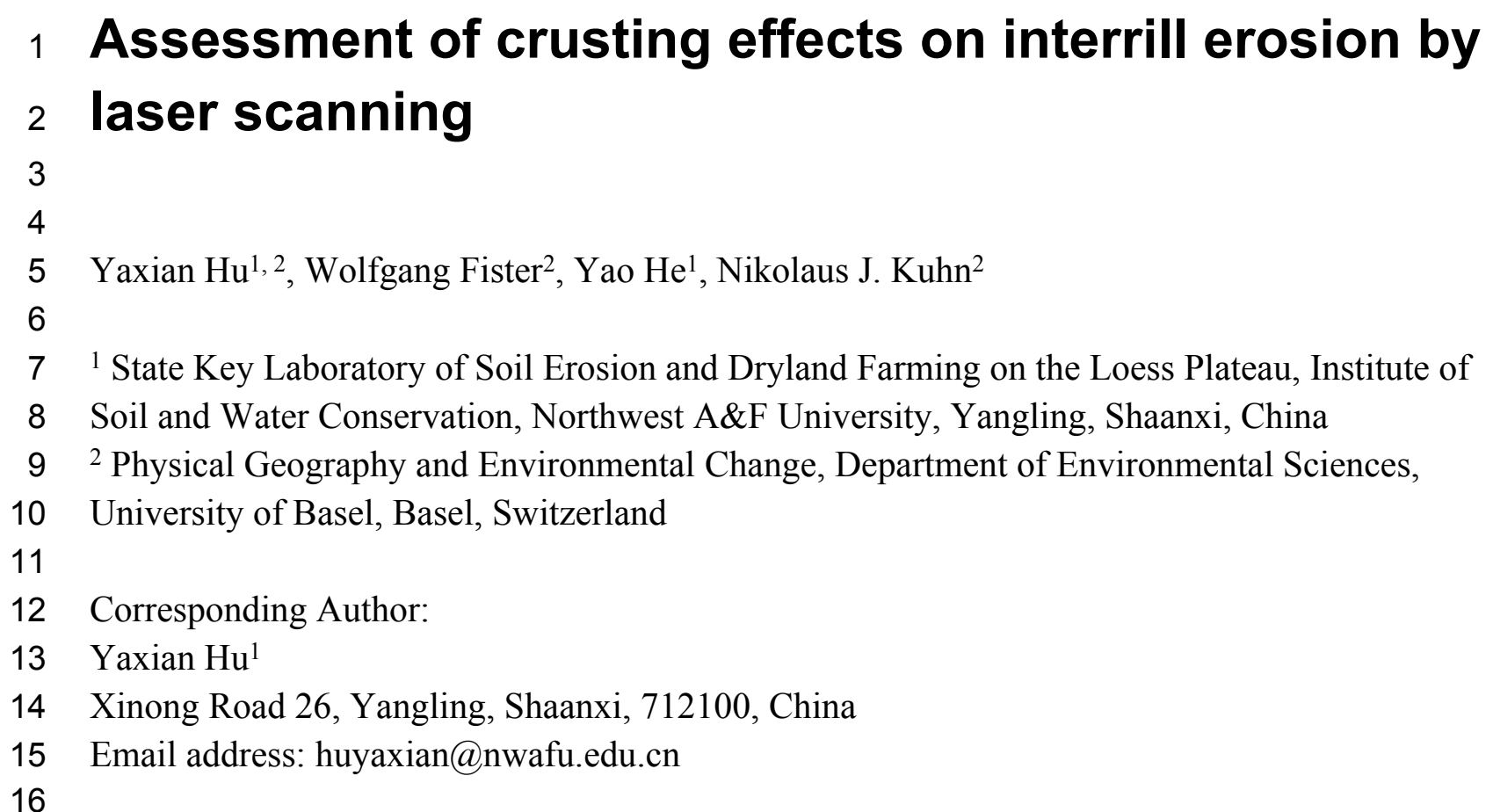




\section{Abstract}

18 Background. Crust formation affects soil erosion by raindrop impacted flow through changing particle size and cohesion between particles on the soil surface, as well as surface microtopography. Therefore, changes in soil microtopography can, in theory, be employed as a proxy to reflect the complex and dynamic interactions between crust formation and erosion caused by raindrop-impacted flow. However, it is unclear whether minor variations of soil microtopography can actually be detected with tools mapping the crust surface, often leaving the interpretation of interrill runoff and erosion dynamics qualitative or even speculative.

Methods. In this study, we used a laser scanner to measure the changes of the microtopography of two soils placed under simulated rainfall in experimental flumes and crusting at different rates. The two soils were of the same texture, but under different land management, and thus organic matter content and aggregate stability. To limit the amount of scanning and data analysis in this exploratory study, two transects and four subplots on each experimental flume were scanned with a laser in one-millimeter interval before and after rainfall simulations.

Results. While both soils experienced a flattening, they displayed different temporal patterns of crust development and associated erosional responses. The laser scanning data also allowed to distinguish the different rates of developments of surface features for replicates with extreme erosional responses. The use of the laser data improved the understanding of crusting effects on soil erosional responses, illustrating that even limited laser scanning provides essential information for quantitatively exploring interrill erosion processes.

\section{Introduction}

39

After decades of improvement by researchers and farmers worldwide, risks of field-scale soil loss can be predicted reasonably well by erosion models such as the Revised Universal Soil Loss Equation (RUSLE) (Wischmeier \& Smith, 1978) or the Water Erosion Prediction Project (WEPP) (Flanagan \& Nearing, 2000). In the latter model, and several other process-based models (e.g., EUROSEM, CREAMS), the contribution of interrill erosion to the overall soil loss has been accounted for in separate sub-models (Knisel \& Nicks, 1980; Morgan et al., 1998; Aksoy \& Kavvas, 2005). Interill erosion comprises soil loss by non-concentrated and raindropimpacted flow (Kinnell, 2005). Fine and light particles enriched in organic matter are often entrained and transported selectively, leading to preferential removal of soil organic carbon and phosphorus, and their transfer into watercourses as non-point source pollution (Sharpley, 1985; Quinton, Catt \& Hess, 2001; Lal, 2003; Teixeira \& Misra, 2005; Warrington et al., 2009; Kuhn et al., 2012; Hu, Fister \& Kuhn, 2013). Therefore, realistic simulation of interrill erosion is essential. A key problem for such modeling is the parameterization of soil resistance to crust formation during one or a sequence of erosion events (Kuhn, Bryan \& Navar, 2003; Kuhn \& Bryan, 2004; Kinnell, 2005; Hu, Fister \& Kuhn, 2016).

When subjected to raindrop impact, the soil surface is compacted, and soil aggregates experience destruction through slaking, swelling, micro-cracking and dispersion (Le Bissonnais, Bruand \& Jamagne, 1989; Le Bissonnais, 1996; Darboux \& Le Bissonnais, 2007). The overall impacts of 
57 these changes of soil surface properties on interrill erosion are ambiguous because they can

58

59

60

61

62

63

64

65

66

67

68

69

70

71

72

73

74

75

76

77

78

79

80

81

82

83

84

85

86

87

88

89

90

91

92

93

94

95

96

induce the formation of cohesive structural crusts, which stabilize the soil surface and protect it from further erosion (Chen et al., 1980; Le Bissonnais, 1990). However, a compacted surface is also smoother, leading to shallower and faster runoff, which increases runoff erosivity (Le Bissonnais, Renaux \& Delouche, 1995; Quinton, Catt \& Hess, 2001; Kuhn, 2007). Meanwhile, the destruction of aggregates generates fine, loose mineral or aggregated fragments that can be transported easily by raindrop-impacted thin flows (Kuhn, Bryan \& Navar, 2003; Anderson \& Kuhn, 2008). Smoothing of the surface, as well as the formation of local surface irregularities also induce differences in runoff depth and thus the way raindrop energy is dissipated on soil surface (Kinnell, 2005). Depending on the flow depth, this may protect soils from erosion, but can also enhance detachment and transport (Torri, Sfalanga \& Chisci, 1987).

The effect of crust formation is not limited to the amount of erosion, but also affects the quality of sediment. Due to its limited runoff energy, erosion by non-concentrated flow often moves fine and light particles, including the substances attached to them, selectively (Basic et al., 2002; Schiettecatte et al., 2008; Kinnell, 2012). Aggregates at the soil surface continue to breakdown into smaller fragments during a rainfall event, discharging loose materials of different sizes and densities (Chen et al., 1980). Sediment of varying size compositions is thus enriched differently with nutrients and organic matter, posing unknown pollution risks to downstream watercourses (Kuhn et al., 2012; Hu, Fister \& Kuhn, 2013). The variations of sediment composition do not only depend on the changes of stability and transportability of surface materials over time, but are also affected by surface roughness and its interaction with rainfall and runoff (Moore \& Singer, 1990; Kuhn, Bryan \& Navar, 2003). Furthermore, on soils with mixed texture and stable small aggregates, the initial removal of loose minerals and aggregated particles progressively exposes cohesive structural crust, leading to a distinct temporal pattern of initially high and then declining erosion rates (Moore \& Singer, 1990; Kuhn, Bryan \& Navar, 2003). In addition, as repeatedly reported in previous studies (Nearing, Govers \& Norton, 1999; Armstrong et al., 2011; Hu, Fister \& Kuhn, 2016), the inter-replicate variability of runoff and soil erosion rates under strictly controlled experimental conditions also illustrates a complex, fine-scale interaction between soil surface microtopography, crust formation and soil particles, including their spatial patterns, that is hardly overcome even by adding more replicates.

The above-described examples of the interaction between crust formation and interrill erosion illustrate the need for spatial data capturing the resistance to erosion (hereafter referred to as erodibility) of soil surface and its change over time. Currently, the lack of such quantitative information introduces uncertainties for interrill erosion modeling (Darboux \& Le Bissonnais, 2007; Bremenfeld, Fiener \& Govers, 2013; Hu, Fister \& Kuhn, 2016). Apart from characterizing the composition and stability of the crust, the change of soil surface roughness over time is an essential variable controlling soil resistance to interrill erosion and sediment quality (Kuhn, Bryan \& Navar, 2003; Armstrong et al., 2012; Kuhn \& Armstrong, 2012). However, soil microtopography changes are difficult to monitor (Issa et al., 2004; Algayer et al., 2014). Studies of soil micromorphology, e.g. Chen et al. (1980), do not capture the appropriate scale, whilst

Peer] reviewing PDF | (2019:10:42555:1:1:NEW 15 Dec 2019) 
97 indirect measurements of roughness on larger areas, for example by detecting directional 98 reflectance of crusts (Anderson \& Kuhn, 2008; Croft, Anderson \& Kuhn, 2012), only provide an 99 index value for roughness. Other recently developed imaging techniques, such as Structure from 100 Motion (SfM), have also been applied to detect small soil surface variations (Vinci et al., 2017;

101 Krenz \& Kuhn, 2019) or to point out the spatial distribution of erosion and deposition hotspots at 102 plot scale (Remke et al., 2016; Krenz \& Kuhn, 2019). Terrestrial or airborne laser scanning have 103 also been widely used to investigate slope-scale rill erosion or catchment-scale gully morphology 104 (Vinci et al., 2015; Wu et al., 2017). However, all these studies and methods lack the millimeter105 scale resolution required for the assessment of crust formation and its effects on flow hydraulics and soil resistance to erosion (Eltner et al., 2015). A method such as laser scanning, at least in a laboratory setting, enables the generation of the most precise digital elevation models. Huang \& Bradford (1992) demonstrated that laser scanning at a $0.5-\mathrm{mm}$ grid resolution can be used to replace speculative explanations of soil erosional responses with more quantitative interpretations. Abban et al. (2017) employed a laser scanner and several indices derived from the obtained data to decipher the role of rain splash on surface roughness. All these studies illustrate that laser scanning has the potential for closing the gap between the ideal quality of data required to assess crusting effects on interrill erosion and a feasible acquisition of soil microtopography in a laboratory setting.

In this study, we carried out high-resolution laser scanning on a laboratory flume to measure changes in crust microtopography before and after a rainfall event. The data were obtained during an experiment that focused on the temporal dynamics of soil erosion by raindropimpacted flow on two soils of similar texture, but with different land management, organic matter content and aggregate stability (Hu, Fister \& Kuhn, 2013). We hypothesized that the highresolution laser scanning signals were sufficiently sensitive to detect minor changes of soil microtopography induced by crust formation, and thus can be employed to quantitatively explain differences of soil erosional responses between soils subject to different land management. Such use of laser scanning would avoid the often qualitative explanations for differences in interrill erosion between events or soils of different quality.

\section{Materials \& Methods}

\section{Experimental design and soil sampling}

Two silty loams of similar texture, but different soil organic carbon content (SOC) and aggregate stability (Table 1), were subject to prolonged rainfall simulations in this study. The surface of the two soils were laser scanned before and after the rainfall events to detect the crusting-induced changes of soil microtopography and the effect on erosion by raindrop-impacted flow. As part of a series of experiments, detailed information on soil properties and experimental design have been described in $\mathrm{Hu}$ et al. (2013). In brief, the two soils, one conventionally (CS) and one organically managed (OS), were sampled in 2010 from A-horizons on two farms near Möhlin $\left(47^{\circ} 33^{\prime} \mathrm{N}, 7^{\circ} 50^{\prime} \mathrm{E}\right)$ in northwest Switzerland. After drying at $40^{\circ} \mathrm{C}$, the two soils were sieved into 1 to $8 \mathrm{~mm}$ to exclude over-sized clods and to allow the observation of relative changes in surface 
137 roughness during erosion processes. Immediately after sieving, each of the soils was filled into a

138 round flume (Figure 1a), with an outer ring of $50 \mathrm{~cm}$ in diameter and an opening of $10 \mathrm{~cm}$ in the

139

140

141

142

143

144

145

146

147

148

149

150

151

152

153

154

155

156

157

158

159

160

161

162

163

164

165

166

167

168

169

170

171

172

173

174

175

176 center (Figure 1b). The slope between the outer edge and the inner opening was $10 \%$. To facilitate drainage, the floor of the flumes was perforated and covered by a fine cloth and a layer of sand (approximately $2 \mathrm{~cm}$ ). This design of the flumes created a relatively uniform pattern of erosion processes along a short slope with a surface area that generated sufficient runoff and sediment for further analysis.

\section{Prewetting and prolonged rainfall simulations}

In order to facilitate the generation of runoff and enable the observation of the effects of aggregate breakdown during crusting over the actual rainfall events on the following day, the two flumes were first subjected to a pre-wetting rainfall at an intensity of $30 \mathrm{~mm} \mathrm{~h}^{-1}$ for $30 \mathrm{~min}$ right after the soil had been placed into the flume (Figure 1c). The intensity of the actual rainfall was also $30 \mathrm{~mm} \mathrm{~h}^{-1}$, but it lasted for $360 \mathrm{~min}$, long enough to achieve prolonged steady-state runoff and associated erosional responses. A Fulljet nozzle (Spraying Systems 1/4 HH14WSQ) was used to generate multiple-sized raindrops $\left(\mathrm{D}_{50}\right.$ of $\left.2.3 \mathrm{~mm}\right)$ with an average kinetic energy of $113.9 \mathrm{~J} \mathrm{~m}^{-2} \mathrm{~h}^{-1}$ (measured by a Joss Waldvogel-Disdrometer). While the lower kinetic energy of the rainfall compensates to a certain extent for the high intensity, the design of the experiment did not aim at the strict simulation of natural conditions, but focused on identifying the effects of crust formation on erosion and sediment properties over time.

During the $360 \mathrm{~min}$ rainfall events, runoff and sediment samples were collected every $30 \mathrm{~min}$ from the inner ring in the center. The total weight of the sediment suspension and the dry weight of the sediment particles were measured to calculate runoff and soil erosion rates. The SOC concentration of each sediment sample was determined using a LECO RC 612 at $550^{\circ} \mathrm{C}$. The enrichment ratio of eroded SOC (ERsoc) was calculated between the SOC concentration of the eroded sediment and that of the original soil (Hu, Fister \& Kuhn, 2013). After the $360 \mathrm{~min}$ prolonged rainfall events, the round flumes were oven-dried at $40^{\circ} \mathrm{C}$, and the loose material on each round flume was then collected by a vacuum cleaner and weighed (after scanning). The entire experiment was repeated twelve times, but due to technical failure, only the data from the latter 10 replicates (replicate number 3 to 12) were used in this study.

\section{Laser scanning of soil surface}

To capture the changes of soil surface induced by rainfall and erosion, each flume was laserscanned three times (Figure 1d): first in the dry condition after filling the soil in the flume (hereafter termed as "Before"); second, after the $30 \mathrm{~min}$ prewetting event (hereafter termed as "Prewetted"); and finally, after the 360 min rainfall event (hereafter termed as "After"). The laser was connected to a laptop and data recording was carried out using a MatLab routine. The scanned data were recorded as $\mathrm{x}-, \mathrm{y}-$, and $\mathrm{z}$-values.

During each laser scanning, two transects $(a, b)$ and four sub-plots (a, b, c, d, each $5 \mathrm{~cm} \times 18 \mathrm{~cm}$ ) were scanned (Figure 1e). The two transects crossed at the center of the flume, and each transect 
177 was scanned stepwise at a $1 \mathrm{~mm}$ resolution, in sequence detecting 500 scanning points (Figure

178 1e). On each of the four subplots (each $90 \mathrm{~cm}^{2}$ ), the 500 scanning points were visited

179 automatically following the path calculated by the scanning system, and in total covered about

$18019 \%$ of the entire eroding area $\left(1884 \mathrm{~cm}^{2}\right)$ (Figure 1e). Since similar raindrop-impacted flow

181 would be dominant on the erosion plots, the soil surface microtopography was presumed to be

182 spatially uniform on each plot. Therefore, two transects and four subplots were considered

183 adequately representative to investigate erosion-induced changes of surface microtopography. In

184 order to ensure precise alignment, the flume was accurately positioned at bottom left-hand corner

185 of the scanning frame prior to each scanning run (Figure $1 \mathrm{~d})$ and accordingly coordinated as $(0$,

186 0). By doing so, we made sure that each time the same area of the flume was scanned.

187 The laser scanner used in this study (Figure 1d) was custom-designed and built at the University

188 of Basel based on a design used by Anderson \& Kuhn (2008) and Croft, Anderson \& Kuhn

189 (2009). It consisted of a combined laboratory laser and sensor, manufactured by Baumer Electric,

190 Frauenfeld, Switzerland (model number OADM 2014471/S14C), working at a wavelength of

$191675 \mathrm{~nm}$ and suited to measure distances of up to five meters at an accuracy of $0.1 \mathrm{~mm}$ (Brunton,

192 2004). The laser was mounted in one-by-one metre frame where it could be moved with stepper

193 motors in a pre-programmed way using a Stepper Motor Controller CSD 315 (Isel Automation,

194 Germany).

195

196 Calculation of soil surface elevation across two transects and four subplots

197 Since the laser scanning was conducted stepwise over two transects and four subplots with strict

198 alignment, the linear route of the former and the programmed route of the latter enabled a

199 pairwise comparison of the elevation of individual scanning points. In addition, although interrill

200 erosion did not form concentrated flow on the small round flume used in this study, the tilted soil

201 surface provided a predominant runoff direction, which was parallel to the scanned transects.

202 Therefore, with limited scanning data and pairwise comparison, the height distribution of

203 scanning points was considered adequate to serve the purpose of comparing the minor variations

204 in surface microtopography induced by crusting and their impacts on soil erosional responses

205 (Croft, Anderson \& Kuhn, 2009; Vinci et al., 2015).

206 By conducting regression analysis with the laser signals (the space between the scanner frame

207 and the soil surface), the actual height of each point was calculated using Eq. (1):

$208 H_{i}=\max \left\{z_{1}, z_{2}, z_{3}, \cdots, z_{500}\right\}-\left(z_{i} \times 4.8619+0.1491\right)$

209 Where, $H_{i}$ is the height of each data point $(\mathrm{mm}) ; z_{i}$ is the distance between the laser and soil

210 surface of each data point; $\max \left\{z_{1}, z_{2}, z_{3}, \cdots, z_{500}\right\}$ is the longest distance between the laser and

211 soil surface of all the points (namely the zero-level elevation); $i$ is in sequence from the $1^{\text {st }}$ to the

$212500^{\text {th }}$ scanning point; the constants 4.8619 and 0.1491 are the regression coefficients.

213 To exclude the distorted points around the opening in the center, as well these immediately

214 nearby the outer ring (Figure 1b), only two subsections on each side of the two transects were

215 analyzed: $91 \leq i \leq 200$ on the left half and $311 \leq i \leq 420$ on the right half of the $X$ axis.

Peer] reviewing PDF | (2019:10:42555:1:1:NEW 15 Dec 2019) 
216 Furthermore, to eliminate the bias introduced by the original slope steepness and to better reflect

217 the relative surface height changes at local scale, the heights of each data point along the two

218 transects were standardized by the slope steepness and the distance from the lowest edge to the

219 targeted point (Eq. 2, 3). The sample protocol was also applied for the subsections of the upper 220 and lower half of the $Y$ axis.

221

$h_{i}=H_{i}-\left(\max \left\{x_{91}, x_{92}, x_{93}, \cdots, x_{200}\right\}-x_{i}\right) \times 10 \%$

222

223

or,

$h_{i}=H_{i}-\left(x_{i}-\min \left\{x_{311}, x_{312}, x_{313}, \cdots, x_{420}\right\}\right) \times 10 \%$

224

225

226

227

228

229

230

231

232

233

234

235

236

237

238

239

240

241

242

243

244

245

246

247

248

249

250

251

252

253

254

As there were no center opening or edge effects on the four subplots (Figure 1e), all the 500 data points of each subplot were analyzed. Since the bias possibly introduced by the original slope steepness of $10 \%$ was systematic and limited to the four subplots with small areas $(5 \mathrm{~cm} \times 18$ $\mathrm{cm}$ ), the $H_{i}$ of each scanning point inside the subplots was not standardized to slope steepness in this study. Moreover, to quantitatively compare height distributions in the four subplots, all the measured heights were then classified into eight height classes: $<3 \mathrm{~mm}, 3-4 \mathrm{~mm}, 4-5 \mathrm{~mm}, 5-6$ $\mathrm{mm}, 6-7 \mathrm{~mm}, 7-8 \mathrm{~mm}, 8-9 \mathrm{~mm}$ and $>9 \mathrm{~mm}$. To visualize the changes of surface roughness after erosion events, the variogram analysis of the four subplots were conducted using GS+ (Geostatistics for the Environmental Sciences). Kriging regression was applied to give the best linear unbiased prediction of the intermediate values, which were then employed to plot a 2-D version of soil surface height distribution for each subplot. In addition, the height differences between Before, Prewetted and After tests with the least and most eroded replicates were also compared to detect whether the erosion processes were the same, but just operating at different rates, or whether the soil surfaces developed in different ways and thus leading to different erosion processes.

\section{Results}

\section{Soil erosional responses and enrichment ratio of eroded SOC}

The soil erosional responses observed during the experiments are reported in detail in $\mathrm{Hu}$ et al. (2013) and only summarized here briefly (Table 2). Rates of runoff and soil erosion, and enrichment ratio of organic carbon in the eroded sediment (ERsoc) showed clear temporal patterns. The runoff on the CS increased and reached a steady state of $12.9 \mathrm{~mm} \mathrm{~h}^{-1}$ state-after 180 min, while the runoff on the OS required $240 \mathrm{~min}$ to stabilize at $10.7 \mathrm{~mm} \mathrm{~h}^{-1}$. As runoff increased over rainfall time, the soil erosion rate of the CS increased first, peaked when runoff rate reached steady state and decreased afterwards. The ERsoc of the CS peaked at 1.94 around $150 \mathrm{~min}$, while that of the OS reached only 1.44 after $330 \mathrm{~min}$ (Table 2). Further information on soil erosional response on the CS and OS are listed in Table 2.

A further noteworthy result is the inter-replicate variability, which remained between 15 and $39 \%$ even after the maximum runoff and erosion were reached (Hu, Fister \& Kuhn, 2016). Out of the ten times repeated simulations, the least and most eroded replicate for the CS were CS-4 and CS-11, and replicate OS-9 and OS-12 for the OS (Table 3). Typically, the total runoff, soil 
255

256

257

258

259

260

261

262

263

264

265

266

267

268

269

270

271

272

273

274

275

276

277

\section{8}

279

280

281

282

283

284

285

286

287

288

289

290

291

292

293

erosion and SOC loss of the most eroded replicates nearly doubled that on the least eroded replicate, even though they received comparable rainfall amount (Table 3).

\section{Changes of soil surface elevations across the two transects}

Figure 2 shows the changes of the soil surface at different conditions (Before, Prewetted, After and Post-dried). After 360 min prolonged rainfall, the CS surface was visibly smoother with extended flat areas and few loose material $\left(10.96 \pm 3.01 \mathrm{~g} \mathrm{~m}^{-2}\right.$ as listed in Table 3), whereas the OS surface was covered to a greater extent by degraded aggregates $\left(43.78 \pm 11.40 \mathrm{~g} \mathrm{~m}^{-2}\right.$ as listed in Table 3). The surface elevation changes of the CS and OS are illustrated in Figure 3. For both soils, the soil surface was lowered after the two rainfall events, with a reduction most evident after the 360 min prolonged rainfall (Figure 3).

Apart from the average changes of surface elevation, Figure 4 further compares the height differences between the least and most eroded replicate under the three conditions (Before, Prewetted and After). The height differences between the Prewetted and Before were more closely clustered than that between the After and Before (Figure 4a vs. 4b, 4c vs. 4d).

Specifically, for the height differences between After and Before on the CS (Figure 4b), the most eroded replicate CS-11 had more negative height differences (point clouds $<0$ ) than increases (point clouds $>0$ ) when compared to the least eroded replicate CS-4. Similar, but more frequent negative height differences, were observed on the most eroded replicate OS-12 than that of the least eroded replicate OS-9. Moreover, the point clouds were also more concentrated under the 1:1 ratio for both the pair-comparison of CS-4 against CS-11, and that of OS-9 against OS-12 (Figure 4b, 4d).

\section{Changes of soil surface elevations on the four subplots}

Figure 5 shows that the height distribution of all the four subplots on the CS was greater and more variable than that on the OS. While the surface of both soils progressively approached the lower height classes over time (Figure 5), this transition was much more skewed on the CS, especially after the 360 min prolonged rain (Figure $5 \mathrm{~d}$ ). The differences of surface elevation between the two soils are also illustrated by the 2D classification in Figure 6. The surface elevation of the two soils was quite similar when the soils were dry before the rainfall. After the 30 min of prewetting, the surface of the OS still showed a strong contrast of high and low elevation (Figure 6d, 6e), whilst the surface of the CS was noticeably flattened (Figure 6a, 6b). After the 360 min prolonged rain, the surface height of the CS became lowered to less than $4 \mathrm{~mm}$ (Figure 6c), that of the OS remained rougher between 4.5- and 6.5-mm (Figure 6f).

\section{Discussion}

\section{Temporal patterns of crusting and erosion on differently structured silty loams}

Given the limited runoff depth and erosion capacity of thin flow, interrill erosion is mostly attributed to raindrops impacting the flow (Kinnell, 2005). Hu, Fister \& Kuhn (2013) speculated 
294 that the differences in erosion and sediment properties observed between the two soils tested in 295 this study were associated with crust formation. They hypothesized that the different erosional 296 responses of the similarly textured CS and OS (Table 2) reflect the influence of aggregate 297 stability (Table 1) on surface crusting and in turn, the capacity of raindrop impacted flow for 298 erosion. In particular, testing the hypotheses of Hu, Fister \& Kuhn (2013) requires a quantitative 299 assessment of the potential effects of crusting on soil surface microtopographic changes over

300

301

302

303

304

305

306

307

308

309

310

311

312

313

314

315

316

317

318

319

320

321

322

323

324

325

326

327

328

329

330

331

332

333 time. The noticeably more pronounced flattening on the CS and the delayed deformation on the OS (Figure 2, 3, 5) confirm the explanation brought forward by Hu, Fister \& Kuhn (2013): greater aggregate stability of the OS slowed aggregate breakdown, maintaining roughness and sediment size for longer, thus also resisting raindrop impact for longer than on the CS. Such potential effects of aggregate stability on surface deformation are reflected by the more pronounced skewing toward the smaller height classes on the CS surface than on the OS surface (Figure 5). Consequently, after the prolonged $360 \mathrm{~min}$ rainfall, the CS surface height was noticeably flattened to be less than $4 \mathrm{~mm}$ (Figure $5 \mathrm{~d}, 6 \mathrm{c}$ ), whereas the soil surface of the OS was much rougher between $4.5 \mathrm{~mm}$ and $6.5 \mathrm{~mm}$ (Figure 6f) and still interspersed by more loose material (Figure $2 \mathrm{~g}, 2 \mathrm{~h}$, Table 3 ). The declining soil erosion rates on the $\mathrm{CS}$ after its runoff rate exceeded $12.9 \mathrm{~mm} \mathrm{~h}^{-1}$ (Table 2) indicate that runoff had overcome transport limitation and reached a supply-limited process after fine, light and loose particles had been selectively eroded (flattened surface in Figure 5d, 6c). Judging from the abundant loose materials remaining on the OS plots (Figure 2g, 2h, Table 2, as well in Hu, Fister \& Kuhn (2013)), it would also eventually reach a supply-limited condition as runoff grew more competent over time by removing loose particles and exposing cohesive crust. This deduction is also supported by the delayed decline of the ERsoc on the OS once runoff rates had stabilized (Table 2).

\section{Variability of crust formation and erosion identified by laser scanning}

Apart from detecting the different erosional responses between the two soil types, the laser scanning also effectively captured the variations of surface microtopography among replicates. The greater amount of points with height differences $<0 \mathrm{~mm}$ for the most eroded replicate CS-11 and OS-12 (Figure 4d) clearly illustrates more advanced smoothening than that for the least replicates CS-4 and OS-9 (Figure 4b). The unbalanced distributions of height differences in the pairwise comparisons (Figure 4) further demonstrate the divergent influences of surface microtopography on the soil erosional responses of the least and most eroded replicates. To be specific, the more concentrated point clouds under the 1:1 ratio line in Figure $4 \mathrm{~b}$ and $4 \mathrm{~d}$ practically represent three scenarios. (1) The positive height differences under the 1:1 ratio line in section I of Figure $4 \mathrm{~b}$ indicate that the scanned surface was rougher after $360 \mathrm{~min}$ of rainfall (After) than before, and such roughening was more pronounced in the least eroded replicate CS4 than the most eroded replicate CS-11. (2) The concentrated cloud in section II of Figure $4 \mathrm{~b}$ displays that certain parts of the least eroded replicate CS-4 became rougher after the prolonged rainfall than Before (positive height differences from $0 \mathrm{~mm}$ to $6 \mathrm{~mm}$ ), whereas some sections of the most eroded replicate CS-11 were flattened after the prolonged rainfall events (negative 
334 height differences from $-6 \mathrm{~mm}$ to $0 \mathrm{~mm}$ ). A similar, but even more obvious concentration of the 335 point cloud can be observed in section II of Figure 4d, illustrating the divergent development of

336

337

338

339

340

341

342

343

344

345

346

347

348

349

350

351

352

353

354

355

356

357

358

359

360

361

362

363

364

365

366

367

368

369

370

371

372

373 soil surface elevation between the least and most eroded replicates of the OS. (3) The negative height differences in section III under the 1:1 ratio line of Figure $4 \mathrm{~b}$ suggest that those areas were smoother after the 360 min rainfall, and the most eroded CS-11 was more smoothened than the least eroded CS-4. All the three scenarios of more pronounced flattening (Figure 4b, 4d) on the most eroded replicates CS-11 and OS-12 are consistent with their nearly doubled runoff and soil loss as opposed to the least eroded replicates CS-4 and OS-9 (Table 3).

The covariance between the observed erosional response and the laser data illustrates the effectiveness of millimeter-resolution laser scanning to detect the minor topographic changes. On the one hand, this not only confirms the decisive role of soil properties such as organic matter content and aggregate stability in crust formation, soil erosional responses and sediment properties (Table 1, 2) (Hu, Fister \& Kuhn, 2013). On the other, the results clearly illustrate that laser data also help to uncover the causes of the $15 \%-39 \%$ inter-replicate variability among the ten simulated rainfall events (Hu, Fister \& Kuhn, 2016) by effectively distinguishing the rates of surface feature development between the most and least eroded replicates (Figure 4, Table 3). Therefore, with limited laser scanning data and pairwise comparison of height distributions, our observations corroborate previous studies where the changes of soil surface microtopography during rainfall events were effectively quantified by laser scanning (Huang \& Bradford, 1992; Abban et al., 2017). Furthermore, our findings show that with laser scanning an improved quantitative interpretation of interrill erosion experiments is possible, which would otherwise have been attributed just in a qualitative way to inherent variability under controlled laboratory conditions (Bryan \& Luk, 1981; Anderson \& Kuhn, 2008; Hu, Fister \& Kuhn, 2016).

\section{Conclusions}

The changes of microtopography of the surface of two soils with different rainfall-erosion interaction were measured by fine-scale laser scanning before and after the application of simulated rainfall. The surface of both soils experienced a flattening, but they displayed persistently different temporal patterns of crust development and associated erosional responses. By effectively distinguishing the minor variations of surface microtopography and thus the rates of surface feature development among the least and most eroded replicates, the height differences detected by laser scanning revealed the causes of the 15\%-39\% inter-replicate variability among the ten simulated rainfall events. This improved the understanding of crusting effects on soil erosional responses and demonstrated that laser scanning can be used to examine interrill erosion with more quantitative interpretations. While a promising tool in the lab, laser data of the degree of accuracy achieved in this study are likely not readily acquirable under field conditions, especially if plots are large and natural rainfalls determine crust formation (Nearing, 1998; Armstrong et al., 2011). However, studies using high resolution laser scanning conducted in the laboratory could be used to develop soil microtopography parameters that can be linked to reflectance data or DEMs derived by Structure from Motion in both laboratory and field and 
374 their relationship to interrill erosion (Anderson \& Kuhn, 2008; Croft, Anderson \& Kuhn, 2009).

375 With the currently rapid development of easily accessible and affordable devices such as smart

376 phones, high-resolution cameras and unmanned aerial vehicles, the associated digital

377 photogrammetry and high-resolution digital elevation models (Eltner et al., 2015; Vinci et al.,

378 2015, 2017), there is a great potential for the development of sensible interrill microtopography

379 parameters and the acquisition of data in laboratory and field to improve soil erosion models.

380

381

382

383

384

385

386

387

388

389

390

391

392

393

394

395

396

397

398

399

400

401

402

403

404

405

406

407

408

409

410

411

412

413

414

415

416

417

\section{Acknowledgements}

The contributions of Ruth Strunk in carrying out the laboratory experiments are thankfully recognized. The critical discussion with Dr. Peter I. A. Kinnell greatly helped to improve the experiment design. The manuscript was also substantially improved after the proofreading by Florence Greenwood, whose passing was too premature and who is still missed by all the coauthors.

\section{References}

Abban BKB, Papanicolaou AN (Thanos), Giannopoulos CP, Dermisis DC, Wacha KM, Wilson CG, Elhakeem M. 2017. Quantifying the changes of soil surface microroughness due to rainfall impact on a smooth surface. Nonlinear Processes in Geophysics 24:569-579. DOI: $10.5194 / \mathrm{npg}-24-569-2017$.

Aksoy H, Kavvas ML. 2005. A review of hillslope and watershed scale erosion and sediment transport models. Catena 64:247-271. DOI: 10.1016/j.catena.2005.08.008.

Algayer B, Wang B, Bourennane H, Zheng F, Duval O, Li G, Le Bissonnais Y, Darboux F. 2014. Aggregate stability of a crusted soil: differences between crust and sub-crust material, and consequences for interrill erodibility assessment. An example from the Loess Plateau of China: Aggregate stability of a crusted soil. European Journal of Soil Science 65:325-335. DOI: 10.1111/ejss.12134.

Anderson K, Kuhn NJ. 2008. Variations in soil structure and reflectance during a controlled crusting experiment. International Journal of Remote Sensing 29:3457-3475. DOI: 10.1080/01431160701767435.

Armstrong A, Quinton JN, Heng BCP, Chandler JH. 2011. Variability of interrill erosion at low slopes. Earth Surface Processes and Landforms 36:97-106. DOI: 10.1002/esp.2024.

Armstrong A, Quinton JN, Heng BCP, Sander GC. 2012. Processes controlling the development of a shielding layer on natural soil. European Journal of Soil Science 63:54-64. DOI: 10.1111/j.1365-2389.2011.01416.x.

Basic F, Kisic I, Nestroy O, Mesic M, Butorac A. 2002. Particle size distribution (texture) of eroded soil material. Journal of Agronomy and Crop Science 188:311-322.

Bremenfeld S, Fiener P, Govers G. 2013. Effects of interrill erosion, soil crusting and soil aggregate breakdown on in situ CO2 effluxes. Catena 104:14-20. DOI: 10.1016/j.catena.2012.12.011.

Brunton DA. 2004. Effects of scale on processes in rill and gully confluences. $\mathrm{PhD}$ thesis Thesis. University of Toronto.

Bryan RB, Luk SH. 1981. Laboratory experiments on the variation of soil erosion under simulated rainfall. Geoderma 26:245-265. 
418 Chen Y, Tarchitzky J, Brouwer J, Morin J, Banin A. 1980. Scanning electron microscope

419

420

421

422

423

424

425

426

427

428

429

430

431

432

433

434

435

436

437

438

439

440

441

442

443

444

445

446

447

448

449

450

451

452

453

454

455

456

457

458

459

460

461 observation on soil crusts and their formation. Soil Science 130:49-55.

Croft H, Anderson K, Kuhn NJ. 2009. Characterizing soil surface roughness using a combined structural and spectral approach. European Journal of Soil Science 60:431-442. DOI: 10.1111/j.1365-2389.2009.01129.x.

Croft H, Anderson K, Kuhn NJ. 2012. Reflectance anisotropy for measuring soil surface roughness of multiple soil types. Catena 93:87-96. DOI: 10.1016/j.catena.2012.01.007.

Darboux F, Le Bissonnais Y. 2007. Changes in structural stability with soil surface crusting: consequences for erodibility estimation. European Journal of Soil Science 58:1107-1114. DOI: $10.1111 / j .1365-2389.2007 .00906 . x$.

Eltner A, Baumgart P, Maas H-G, Faust D. 2015. Multi-temporal UAV data for automatic measurement of rill and interrill erosion on loess soil. Earth Surface Processes and Landforms 40:741-755.

Flanagan DC, Nearing MA. 2000. Sediment particle sorting on hillslope profiles in the WEPP model. Transactions of the ASAE 43:573-583.

$\mathrm{Hu}$ Y, Fister W, Kuhn NJ. 2013. Temporal variation of SOC enrichment from interrill erosion over prolonged rainfall simulations. Agriculture 3:726-740.

Hu Y, Fister W, Kuhn NJ. 2016. Inherent interreplicate variability during small-scale rainfall simulations. Journal of Soils and Sediments:1-6. DOI: 10.1007/s11368-016-1367-8.

Huang C, Bradford JM. 1992. Applications of a laser scanner to quantify soil microtopography. Soil Science Society of America Journal 56:14-21.

Issa OM, Cousin I, Bissonnais YL, Quétin P. 2004. Dynamic evolution of the unsaturated hydraulic conductivity of a developing crust. Earth Surface Processes and Landforms 29:1131-1142. DOI: 10.1002/esp.1107.

Kinnell PIA. 2005. Raindrop impact induced erosion processes and prediction a review. Hydrological Processes 19:2815-2844.

Kinnell PIA. 2012. Raindrop-induced saltation and the enrichment of sediment discharged from sheet and interrill erosion areas. Hydrological Processes 26:1449-1456. DOI: 10.1002/hyp.8270.

Knisel WG, Nicks AD. 1980. CREAMS-A Field Scale Model for Chemicals, Runoff, and Erosion from Agricultural Management Systems. Washington, D.C., US: Department of Agirculture, US.

Krenz J, Kuhn NJ. 2019. Assessing Badland Sediment Sources Using Unmanned Aerial Vehicles. In: Badland Dynamics in the Context of Global Chnage. Chapter 8. Elsevier,.

Kuhn NJ. 2007. Erodibility of soil and organic matter: independence of organic matter resistance to interrill erosion. Earth Surface Processes and Landforms 32:794-802. DOI: 10.1002/esp. 1486.

Kuhn NJ, Armstrong EK. 2012. Erosion of organic matter from sandy soils: Solving the mass balance. Catena 98:87-95. DOI: 10.1016/j.catena.2012.05.014.

Kuhn NJ, Armstrong EK, Ling AC, Connolly KL, Heckrath G. 2012. Interrill erosion of carbon and phosphorus from conventionally and organically farmed Devon silt soils. Catena 91:94-103. DOI: 10.1016/j.catena.2010.10.002.

Kuhn NJ, Bryan RB. 2004. Drying, soil surface condition and interrill erosion on two Ontario soils. Catena 57:113-133. DOI: 10.1016/j.catena.2003.11.001. 
462 Kuhn NJ, Bryan RB, Navar J. 2003. Seal formation and interrill erosion on a smectite-rich

463

464

465

466

467

468

469

470

471

472

473

474

475

476

477

478

479

480

481

482

483

484

485

486

487

488

489

490

491

492

493

494

495

496

497

498

499

500

501

502

503

504

505

506

507
Kastanozem from NE-Mexico. Catena 52:149-169. DOI: 10.1016/S03418162(02)00091-7.

Lal R. 2003. Soil erosion and the global carbon budget. Environment International 29:437-450. DOI: 10.1016/S0160-4120(02)00192-7.

Le Bissonnais Y. 1990. Experimental study and modelling of soil surface crusting processes. Catena Supplement:13-28.

Le Bissonnais Y. 1996. Aggregate stability and assessment of soil crustability and erodibility: I. Theory and methodology. European Journal of Soil Science 47:425-437.

Le Bissonnais Y, Bruand A, Jamagne M. 1989. Laboratory experimental study of soil crusting: Relation between aggregate breakdown mechanisms and crust structure. Catena 16:377392.

Le Bissonnais Y, Renaux B, Delouche H. 1995. Interactions between soil properties and moisture content in crust formation, runoff and interrill erosion from tilled loess soils. Catena 9:151-4.

Moore DC, Singer MJ. 1990. Crust Formation Effects on Soil Erosion Processes. Soil Sci. Soc. Am. J. 54:1117-1123.

Morgan RPC, Quinton JN, Smith RE, Govers G, Poesen JWA, Auerswald K, Chisci G, Torri D, Styczen ME. 1998. The European Soil Erosion Model (EUROSEM): a dynamic approach for predicting sediment transport from fields and small catchments. Earth Surface Processes and Landforms 23:527-544.

Nearing MA. 1998. Why soil erosion models over-predict small soil losses and under-predict large soil losses. Catena 32:15-22.

Quinton JN, Catt JA, Hess TM. 2001. The selective removal of phosphorus from soil: Is event size important? J. Environ. Qual. 30:538-545.

Remke AA, Wirtz S, Brings C, Gronz O, Seeger M, Ries JB. 2016. The SfM-monitored rill experiment, a tool to detect decisive processes? In: Vienna,.

Schiettecatte W, Gabriels D, Cornelis WM, Hofman G. 2008. Enrichment of organic carbon in sediment transport by interrill and rill erosion processes. Soil Sci. Soc. Am. J. 72:50-55.

Sharpley AN. 1985. The Selection Erosion of Plant Nutrients in Runoff. Soil Sci. Soc. Am. J. 49:1527-1534.

Teixeira PC, Misra RK. 2005. Measurement and prediction of nitrogen loss by simulated erosion events on cultivated forest soils of contrasting structure. Soil and Tillage Research 83:204-217. DOI: 10.1016/j.still.2004.07.014.

Torri D, Sfalanga M, Chisci G. 1987. Threshold conditions for incipient rilling. Catena, Supplement 8:97-105.

Vinci A, Brigante R, Francesca T, Mannocchi F, Rodicioni F. 2015. Measuring rill erosion by laser scanning. Catena 124:97-108. DOI: 10.1016/j.catena.2014.09.003.

Vinci A, Francesca T, Brigante R, Mannocchi F, Radicioni F. 2017. A smartphone camera for the structure from motion reconstruction for measuring soil surface variations and soil loss due to erosion. Hydrology Research 48. DOI: 10.2166/nh.2017.075.

Warrington DN, Mamedov AI, Bhardwaj AK, Levy GJ. 2009. Primary particle size distribution of eroded material affected by degree of aggregate slaking and seal development. European Journal of Soil Science 60:84-93. DOI: 10.1111/j.1365-2389.2008.01090.x.

Wischmeier WH, Smith DD. 1978. Predicting Rainfall Erosion Losses (A Guide to Conservation Planning). Washington, D. C.: United States Department of Agriculture (USDA). 
508 Wu H, Xu X, Zheng F, Qin C, Xu H. 2017. Gully Morphological Characteristics in the Loess Hilly-gully Region Based on 3D Laser Scanning Technique: Gully Morphological

510 Characteristics by 3D Laser Scanning Technique. Earth Surface Processes and

511

512 Landforms. DOI: 10.1002/esp.4332. 


\section{Figure 1}

Soil materials and experimental design.

(a) Layout of round flumes; (b) cross-section profile of the round flume; (c) Set-up of rainfall simulation experiment; (d) set-up of laser scanner; (e) scanning routes of two transects and four sub-plots.
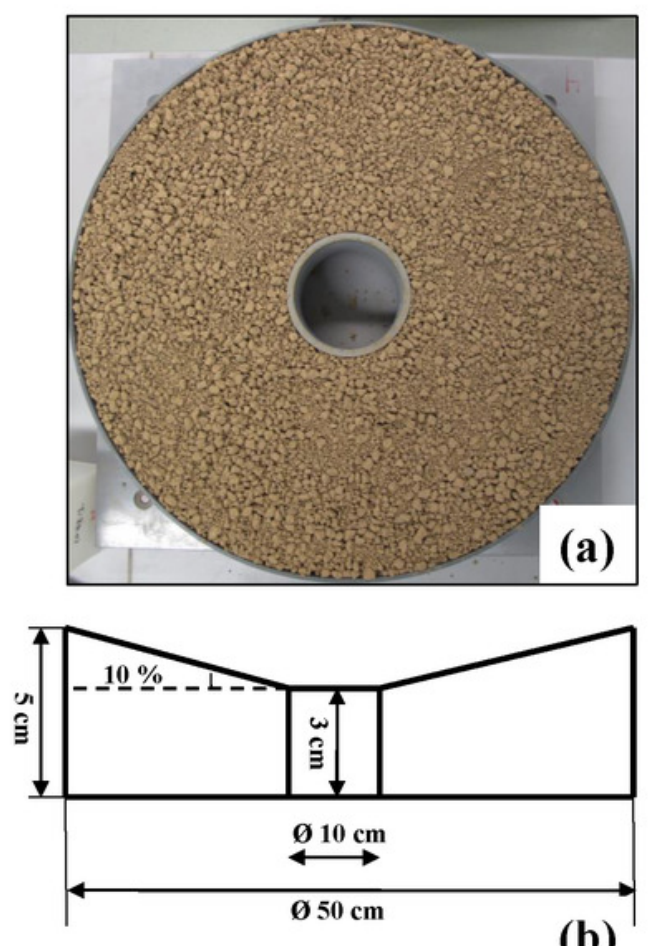

(b)
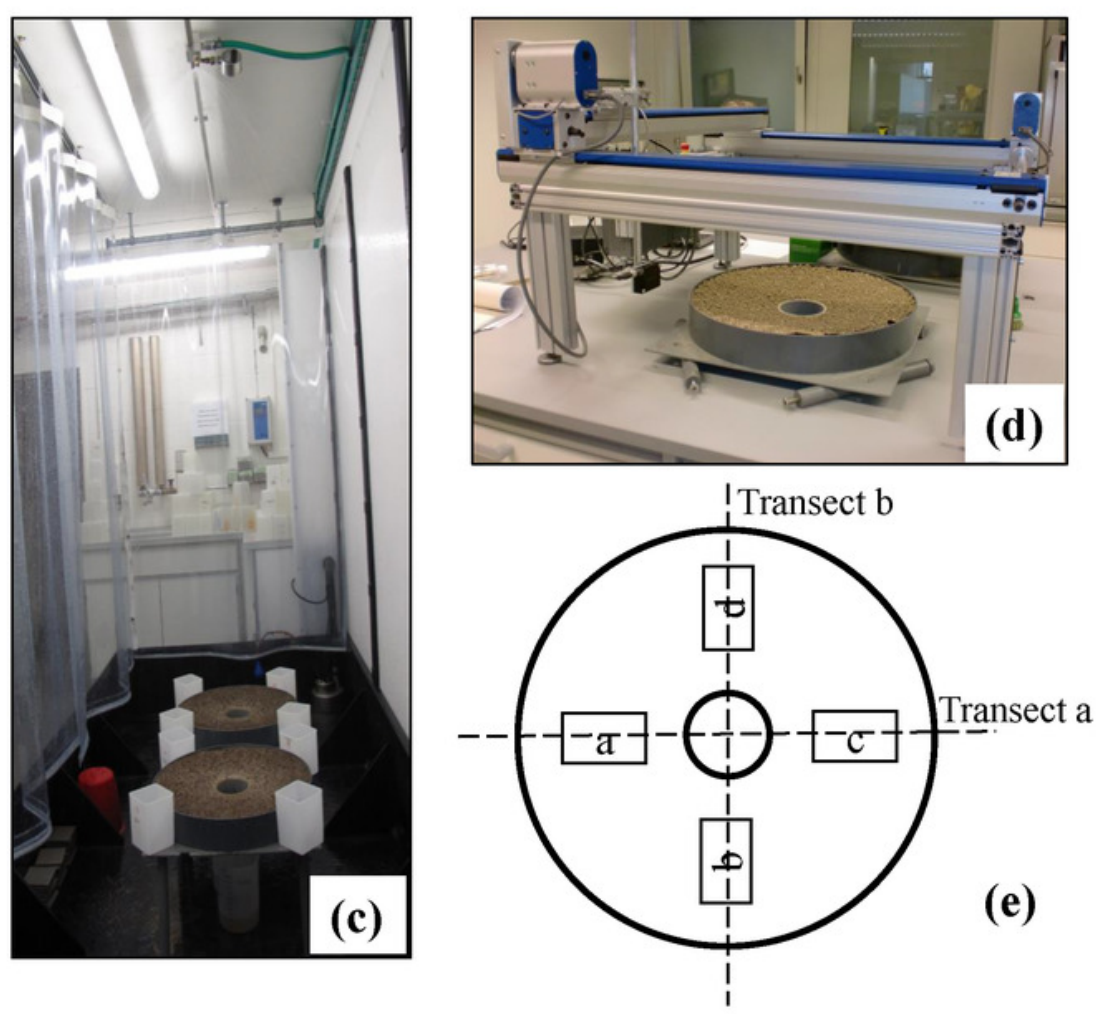


\section{Figure 2}

The changes of the two soils (CS and OS) before (Before), prewetted (Prewetted), after the prolonged rainfall events (After), and Posted-dried.

The dark patches are degraded crumbs and blunted coarse aggregates. Light-colored areas are depositional crusts consisting of loose materials detached by raindrop impact.
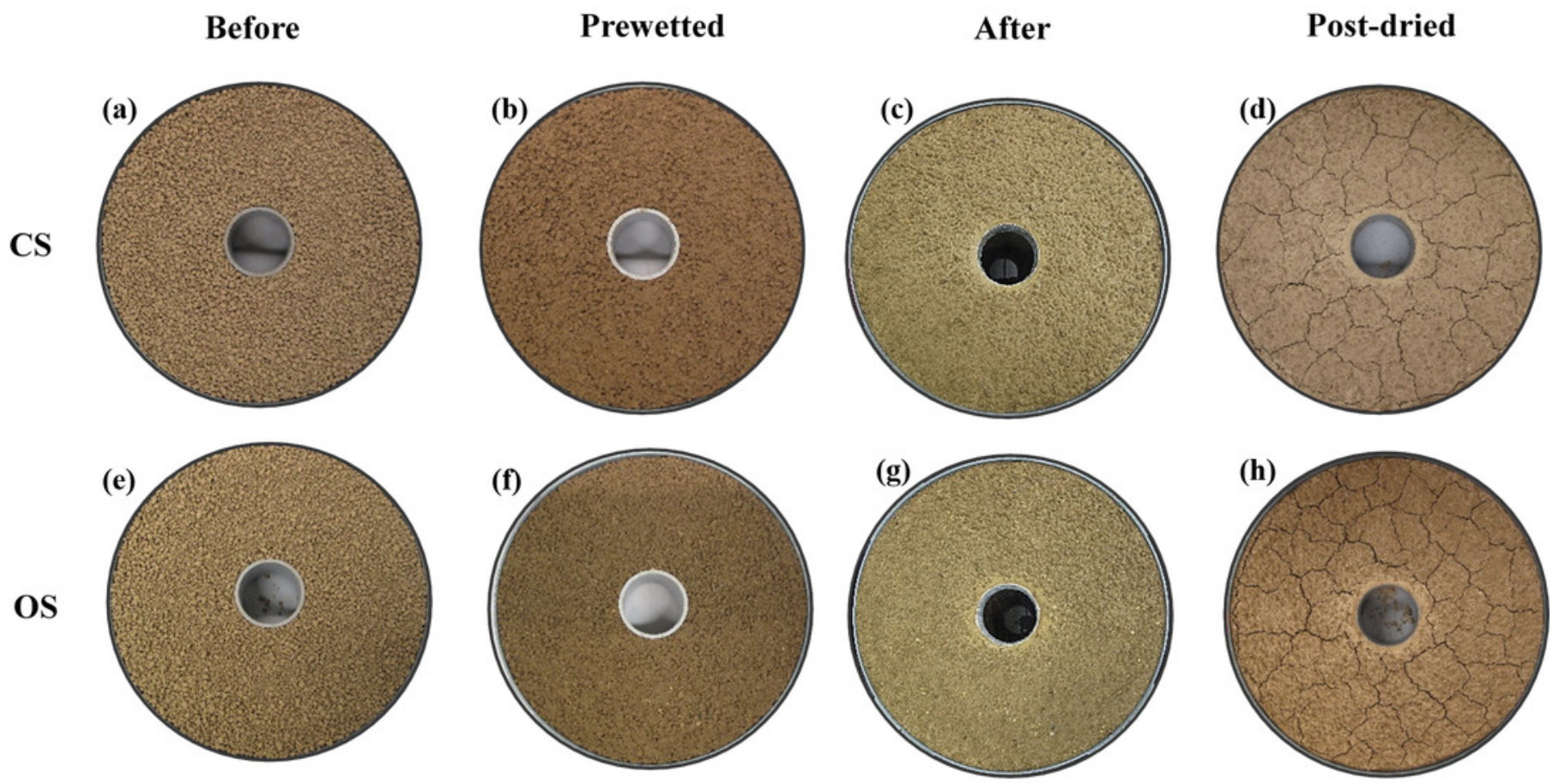
Figure 3

Height of the individual points of the two transects $(a, b)$ of the conventionally farmed soil (CS) and organically farmed soil (OS) Before, Prewetted and After (taking replicate 5 as an example).
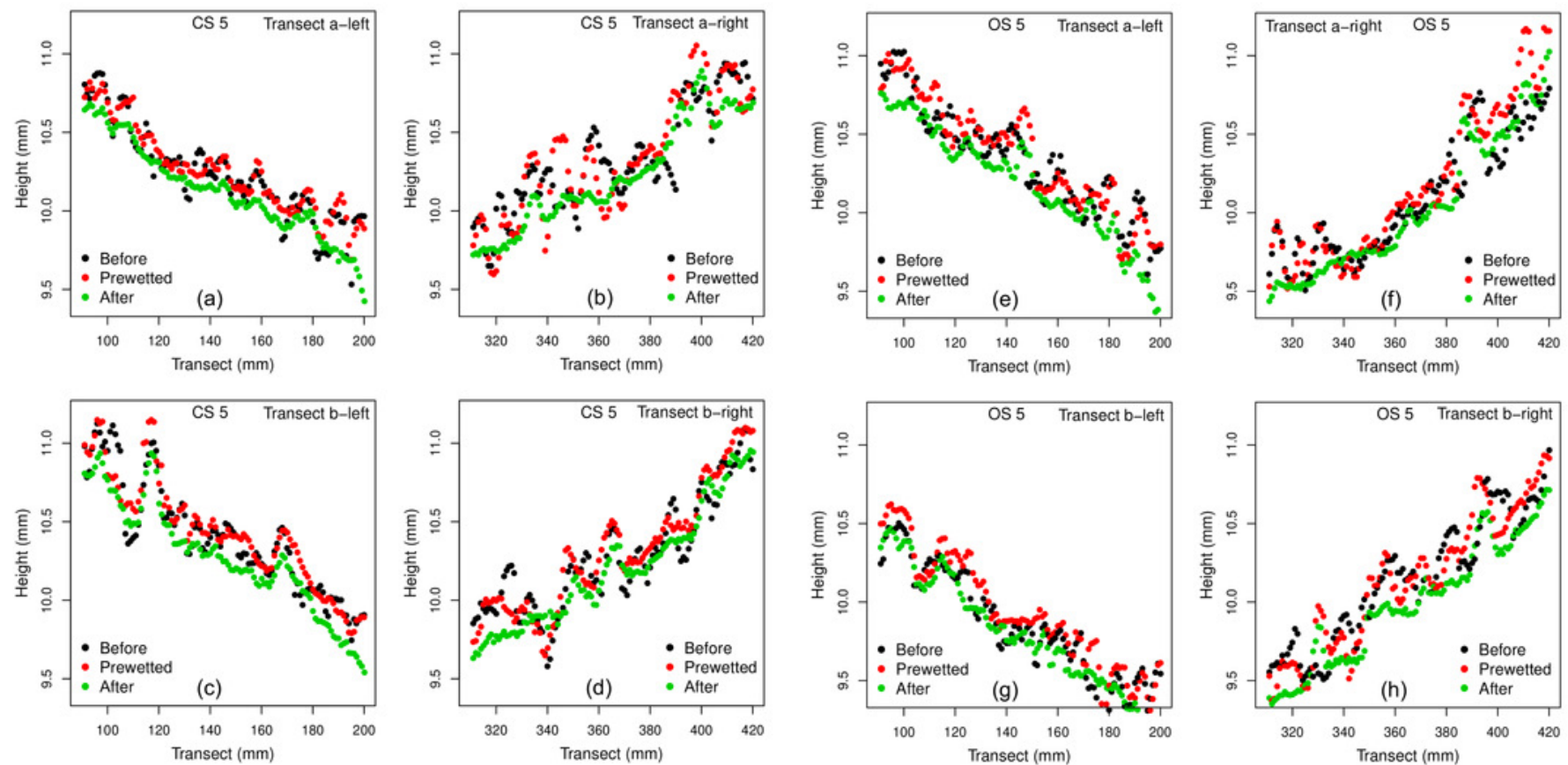
Figure 4

The pair-wise comparison of the normalized height of the two transects on CS-4 vs. CS-11, and OS-9 vs. OS-12.

The replicate CS-4 and OS-9 generated the least soil loss out of the then replicates, whereas the replicate CS-11 and OS-12 produced the most (more information in Table 3). The diagonal line in each subfigure represents the 1:1 ratio. 

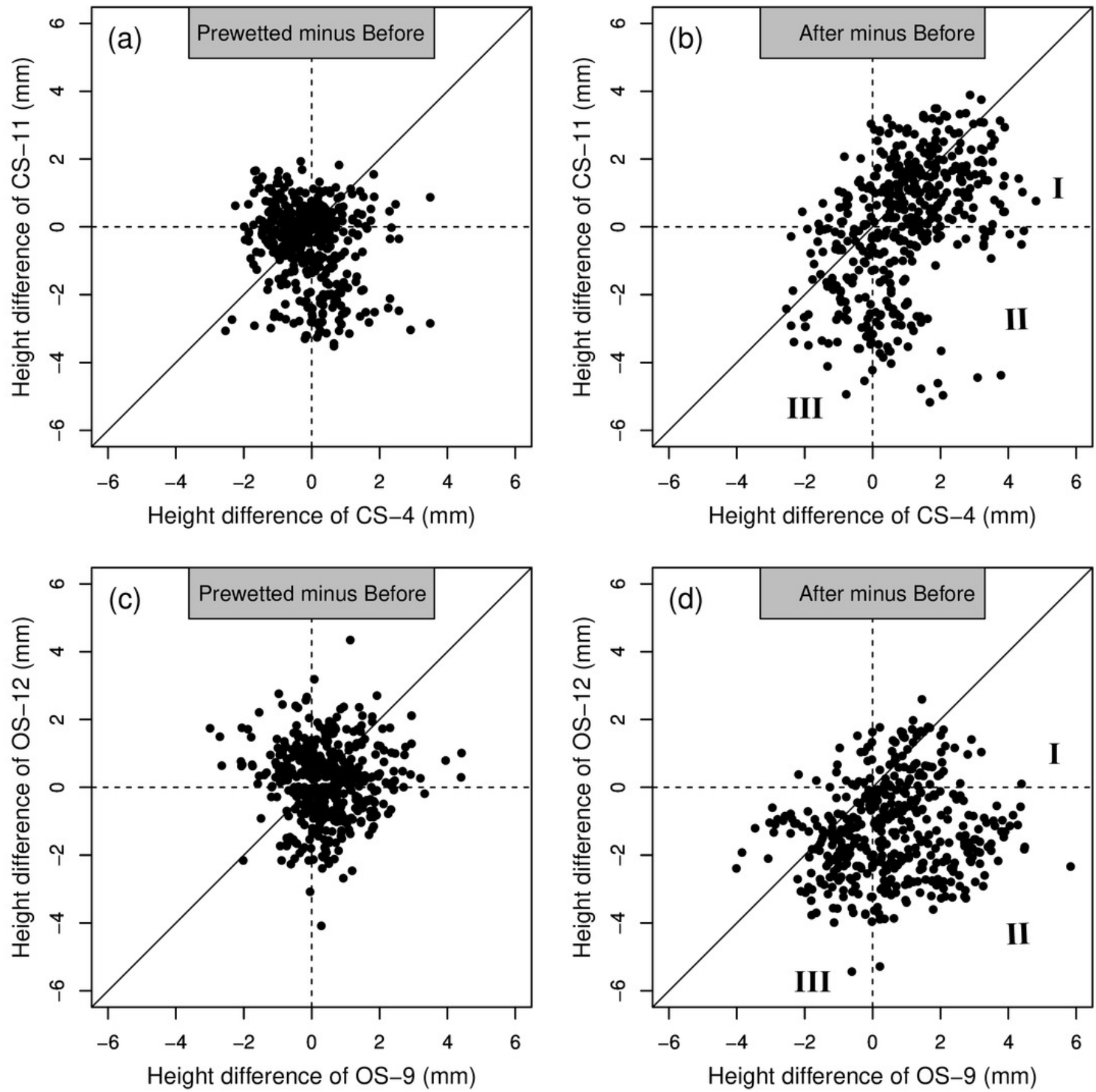
Figure 5

The height distribution on the four subplots of the conventionally farmed soil (CS) and organically farmed soil (OS) Before, Prewetted and After the prolonged rainfall events.

Four subplots over ten replicates combined, namely $n=120$ for the overall, $n=40$ for Before, Prewetted and After.
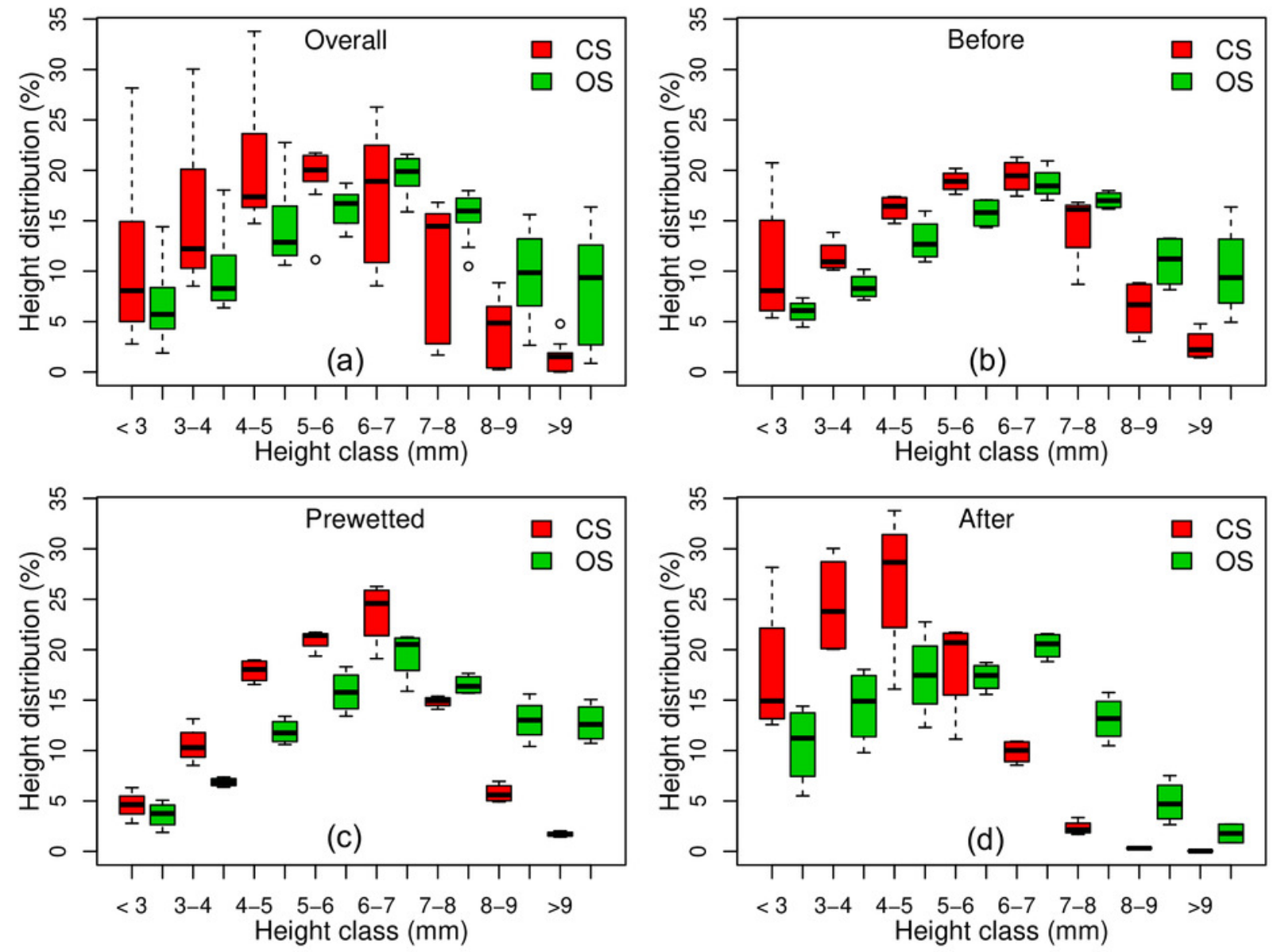


\section{Figure 6}

The surface roughness changes on the subplot $b$ (as an example) of the conventionally farmed soil (CS) and organically farmed soil (OS) Before, Prewetted and After the prolonged rainfall events.

The data was combined from the subplot b over the ten replicates.

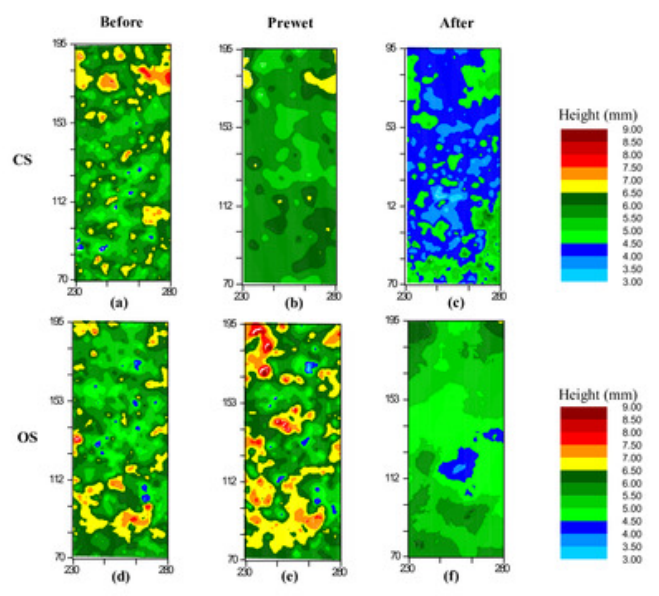




\section{Table $\mathbf{1}$ (on next page)}

Selected properties of the conventionally farmed soil (CS) and organically farmed soil (OS).

Different superscripted letters in each column indicate significant differences (t-test). The subscripted numbers after each average value show the standard deviation $(n=10)$. For more soil properties, please refer to Hu et al. (2013). 


\begin{tabular}{cccccc}
\hline & Clay (\%) & Silt (\%) & Sand (\%) & $\begin{array}{c}\text { Percentage of aggregates } \\
>250 \mu \mathrm{m}(\%)\end{array}$ & $\begin{array}{c}\text { Soil organic } \\
\text { carbon }\left(\mathrm{mg} \mathrm{g}^{-1}\right)\end{array}$ \\
\hline CS & $16.8^{\mathrm{a}}{ }_{1.38}$ & $71.47^{\mathrm{a}}{ }_{1.76}$ & $11.50^{\mathrm{a}}$ & $66.85^{\mathrm{a}}$ & $10.99_{0.05}^{\mathrm{a}}$ \\
OS & $14.39^{\mathrm{b}}{ }_{0.52}$ & $75.84^{\mathrm{b}}{ }_{0.56}$ & $9.77^{\mathrm{b}}$ & $77.76^{\mathrm{b}}$ & $16.9 \mathrm{~b}_{0.10}$ \\
\hline
\end{tabular}

1 


\section{Table 2 (on next page)}

Selected soil erosional responses on the conventionally farmed soil (CS) and organically farmed soil (OS) over the 360 min simulated rainfall events.

The subscripted numbers after each average value show the standard deviation $(n=10)$. 
1

\begin{tabular}{lll}
\hline & CS & OS \\
\hline Time to initiate runoff $(\mathrm{min})$ & 60 & 120 \\
Time to reach runoff steady-state $(\mathrm{min})$ & 180 & 240 \\
Time to reach peak ERsoc $(\mathrm{min})$ & 150 & 330 \\
Average runoff rate at steady-state $\left(\mathrm{mm} \mathrm{h}^{-1}\right)$ & $12.9_{ \pm 0.2}$ & $10.7_{ \pm 0.2}$ \\
Average peak ERsoc & $1.92_{ \pm 0.12}$ & $1.44_{ \pm 0.05}$ \\
Total runoff on average $(\mathrm{mm})$ & $55.6_{ \pm 9.1}$ & $34.1_{ \pm 6.0}$ \\
Total soil loss on average $(\mathrm{g})$ & $27.4_{ \pm 5.0}$ & $16.1_{ \pm 3.0}$ \\
Total SOC loss on average $(\mathrm{mg})$ & $369.1_{ \pm 85.1}$ & $326.0_{ \pm 59.1}$ \\
Loose materials remained on dried flumes $\left(\mathrm{g} \mathrm{m}^{-2}\right)$ & $10.96_{ \pm 3.01}$ & $43.78_{ \pm 11.40}$ \\
\hline
\end{tabular}

2 


\section{Table 3(on next page)}

The erosional responses of the least and most eroded replicates on the conventionally farmed soil (CS) and organically farmed soil (OS) over the 360 min simulated rainfall events. 


\begin{tabular}{|c|c|c|c|c|c|c|}
\hline & & $\begin{array}{l}\text { Total rainfall } \\
(\mathrm{mm})\end{array}$ & $\begin{array}{l}\text { Total runoff } \\
\quad(\mathrm{mm})\end{array}$ & $\begin{array}{l}\text { Total soil loss } \\
\text { (g) }\end{array}$ & $\begin{array}{c}\text { ERsoc } \\
\text { peak }\end{array}$ & $\begin{array}{l}\text { Total SOC } \\
\text { loss (mg) }\end{array}$ \\
\hline \multirow{2}{*}{$\begin{array}{l}\text { Least eroded } \\
\text { replicate }\end{array}$} & CS-4 & 184.55 & 39.00 & 15.53 & 2.01 & 239.16 \\
\hline & OS-9 & 182.20 & 22.55 & 12.20 & 1.38 & 239.70 \\
\hline \multirow{2}{*}{$\begin{array}{l}\text { Most eroded } \\
\text { replicate }\end{array}$} & CS-11 & 181.18 & 66.49 & 37.33 & 1.72 & 453.65 \\
\hline & OS-12 & 188.37 & 42.95 & 22.37 & 1.46 & 441.84 \\
\hline
\end{tabular}

1 